\title{
Quantitative Identification of Middle-Income Trap
}

\author{
Khaled Mohammed Alqahtani ${ }^{1}$ \\ ${ }^{1}$ School of Business, Shaqra University, Saudi Arabia \\ Correspondence: Khaled Mohammed Alqahtani, School of Business, Shaqra University, 11662 Riyadh, P.O. Box \\ 88058, Saudi Arabia.
}

Received: June 26, 2019

Accepted: July 15, $2019 \quad$ Online Published: July 22, 2019

doi:10.5539/ibr.v12n8p81

URL: https://doi.org/10.5539/ibr.v12n8p81

\begin{abstract}
In this research, the growth collapse experienced by 119 economic entities in the world from 1950 to 2010 is quantitatively analyzed. And the objective existence of the middle-income trap is proved from a statistical perspective. On this basis, the existing identification methods of middle-income trap are evaluated and revised. In addition, the late-developing economic entities that have been caught in the middle-income trap in history and the duration of the trap are identified, thus providing several policy references and guidance to step-over the middle-income trap.
\end{abstract}

Keywords: middle-income trap, quantitative identification, stepping-over path

\section{Introduction}

Whether an economy entity is caught in the middle-income trap is usually defined according to whether the time length required for the economy entity to enter the middle-income stage into the high-income stage or the growth rate reaches a certain threshold. However, the existing quantitative identification methods have certain defects and needs to be evaluated and corrected. In this study, comprehensively considering the advantages and disadvantages of the existing methods, and combined with the characteristics of the catch-up process of the late-developing economy entities, a set of quantitative identification methods that are objective, scientific and forward-looking are proposed, thus providing several policy references and guidance to overcome the middle-income trap.

\section{Existing Quantitative Identification Methods of Middle-Income Trap}

There are three existing quantitative identification methods of middle-income trap: the method calculating the span duration threshold; the method calculating relative growth rate; and the method calculating the absolute growth rate.

Felipe et al. define the middle-income trap by calculating the span duration threshold of the middle-income trap. They transformed the World Bank's criteria for classifying economy entities by GNI per capita into the criteria for classifying economy entities by GDP per capita of Maddison' Estimates, dividing 124 economy entities into low-income group (GDP per capita is less than US\$2,000), lower middle-income group (GDP per capita is US\$2,000 to US\$ 7,250), upper middle-income group (GDP per capita is US\$7,250 to US\$11,750) and high-income group (GDP per capita is higher than US\$11,750), and observed the duration of stay of various economies in different income groups from 1950 to 2010. By calculating the median of the duration of stay of the economy entities that entered the lower middle-income group after 1950 to reach the upper middle-income group and the high-income group, it is concluded that: if it takes more than 28 years to enter the upper middle-income group from the lower middle-income group, it is called to be caught in "lower middle-income trap"; if it takes more than 14 years to enter the high-income group from the upper middle-income group, it is called to be caught in "upper middle-income trap".

The identification method of the middle-income trap based on the span duration threshold has two main defects: Firstly, the existence advantages of late developing economy entities are not considered in the identification process. Due to the existence of conditional convergence in economic growth, there is a statistically significant relationship between the length of spanning a duration of the economy entity and the time point spanning the "middle-income trap." Through a simple regression to economy entities successfully spanning, it can be concluded that: If the spanning time point delays for one year, the number of years spanning the lower middle-income trap will be shortened by 0.6 years on average, while the number of years spanning the upper 
middle-income trap will be shortened by 0.24 years on average. If the 14 -year threshold standard is followed, it can be found that most developed economy entities in Europe and the United States have ever been caught in the upper middle-income trap, while neither Japan nor the Four Asian Tigers have ever been caught in this trap. Secondly, the identification standard of a median number of years is too subjective, and the identification results are extremely dependent on the sampled economy entities. For example, Han Wenlong et al. adopted the same calculation method. After removing a small number of samples, the threshold number of years of economy entities successfully spanning the lower middle-income trap and upper middle-income trap are changed to 25 years and 15 years, respectively. Judging by this new threshold, the number of economy entities that were caught in the upper middle-income trap in 2010 decreased by $60 \%$ compared with that judged by the original threshold, which is obviously unreasonable.

Realized the defects of the method of span duration threshold, Aiyar et al. proposed an identification method for calculating the slowdown of the real economic growth rate of the economy entity relative to the theoretically expected growth rate from the conditional convergence framework of the growth theory, and with Penn World Table Version 7.1. They used the average growth rate of GDP per capita of 138 economy entities every five years from 1955 to 2009 for the regression of the lag one-period terms, material and human capital of GDP per capita. When the difference between the actual growth rate of GDP per capita and the expected growth rate estimated by the regression model in the previous five years deviates from $20 \%$ of that in the next five years, it is judged that the economy entity experienced a sustained slowdown and was caught in the middle-income trap in this decade.

This method calculating the relative retardation has solved partial defects existed in the method of span duration threshold, but two more serious new problems are caused: Firstly, it is too strict to use the balanced growth rate lower than the economy entity itself as the identification standard, which will cause that many economies with high growth rate but large fluctuations are included in the trap. Secondly, the basic unit of measurement with ten years as a trap interval is too wide, which will include many years that were not in the trap in the trap. For example, using the same calculation method, Lin Zhifan found that China during 20 years from 1981 to 2000 unexpectedly is in the middle-income trap. This is not only contrary to the objective facts, but also very different from the results obtained by other identification methods. According to the identification method of Felipe et al., it took only 17 years for China to span the lower middle-income trap. Not only this span is significantly lower than the trap threshold of 28 years, but also China used the shortest time in all economy entities spanning this trap after 1950, which is exemplary.

Compared with the first two identification methods, the identification results of the method of Eichengreen et al. by calculating the slowdown of absolute growth rate do not depend on the short-term fluctuations of the identified economy entities and do not change with the change of the scope of the sampled economy entities. Based on the identification method of growth speedup put forward by Hausmann et al., the Growth Collapses standard for the economy entities to be caught in the middle-income trap was given: Firstly, the average growth rate of this economy entity in the seven years before the slowdown was greater than or equal to $3.5 \%$; Secondly, the average growth rate in the seven years after the slowdown is more than $2 \%$ lower than that in the seven years before the slowdown; Thirdly, according to the Penn World Table, GDP per capita of this economy entity is more than US $\$ 10,000$.

The main problem of this identification method is that the standard of $3.5 \%$ and $2 \%$ is relatively subjective, and the identification results will change according to different data sources. For example, Zou Wei and Nan Yu identified that China had 6 slowdown points from 1960 to 2012 after changing the data source to WDI database, which is very different from the result of using Madison database to identify that China had no slowdown points during this period. Besides, the identification objects of this identification method also have a deviation. According to the estimate of Aiyar et al., based on World Table Version 7.1, the middle-income level is between US\$2,000 and US\$15,000, and the standard of GDP per capita greater than US\$10,000 excludes most lower middle-income economy entities and includes all high-income economy entities. Therefore, the traps identified by this method are actually a mixture of upper middle-income trap and high-income trap and cannot be called the real middle-income trap.

To sum up, in this research, when the quantitative identification standard of middle-income trap is formulated, a set of quantitative identification methods that are objective, scientific and forward-looking must be proposed in consideration of the advantages and disadvantages of the span duration threshold method, the relative growth rate slowdown method and the absolute growth rate slowdown method, and combined with the characteristics of the catch-up process of the late-developing economy entities. 


\section{Revised Quantitative Identification Methods of Middle-Income Trap}

In order to identify the middle-income trap, in this research, the first two slowdown standards of growth collapse put forward by Eichengreen et al. are followed. However, the research results of Felipe et al. are referred in grouping standard of various economy entities. Specifically, 119 economy entities from 1950 to 2010 are analyzed with the latest 2013 edition of Maddison Project Database. The years, in which the average growth rate of each economy entity in the seven years before the slowdown is greater than or equal to $3.5 \%$, but that in the seven years after the slowdown is lower than that in the seven years before the slowdown by more than $2 \%$, are marked. Then the marked years are divided into low-income group, lower middle-income group, upper middle-income group and high-income group according to the GDP per capita of the economy entity in that year. In this research, the probability of being caught in the trap is calculated according to the proportion of the number of years in which the trap appears in each stage to the total number of years in which the trap appears, from which Figure 1 can be gained. As can be seen from Figure 1, the sum of the probability of the lower middle-income trap and the upper middle-income trap is $51.73 \%$, which is greater than the probability of the low income trap and much greater than that of the high income trap. This shows that the middle-income trap does exist, and lower middle-income economy entities are more likely to be caught in the trap than middle-income economy entities.

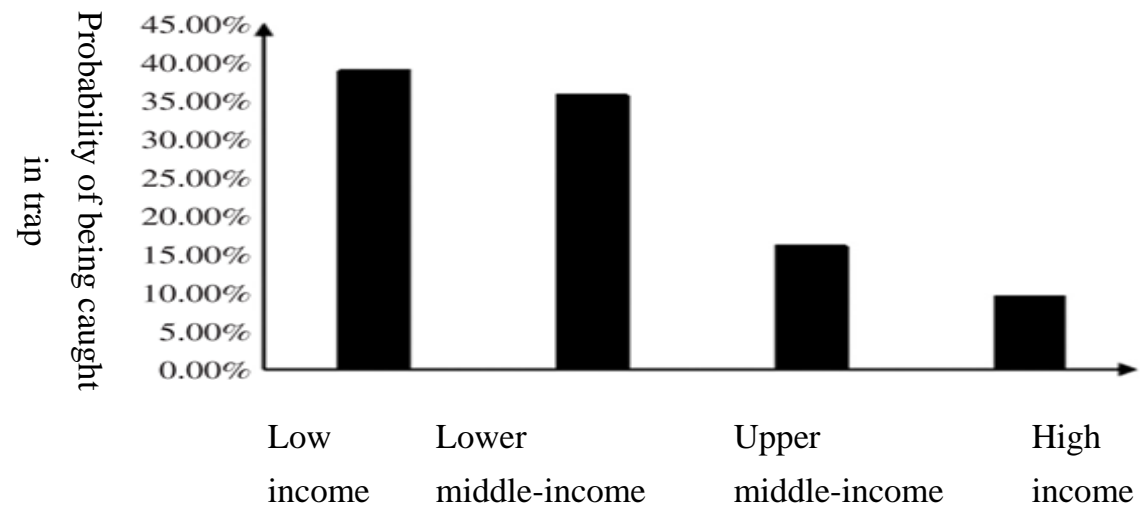

Income group

Figure 1. Probability that the economy entities in each income group are caught in "Growth Collapses"

Next, Smell Test is used to test and calibrate the identification results to observe whether it not only can perfectly identify the empirical facts that some Latin American economy entities in the 1970s and 1980s and some Asian economy entities in 1990s were caught in the middle-income trap, but also will not misjudge other economy entities that successfully spanned the middle-income trap.

By comparing empirical facts, it is found that according to the calculation standard of Eichengreen et al., although all the internationally recognized economy entities caught in the middle-income trap are included, many economy entities that successfully spanned the middle-income trap are also included. For example, Singapore and South Korea had both been caught in the lower middle-income trap for six years and the upper middle-income trap for two years. In other words, the standard proposed by Eichengreen et al. has the problem of excessive identification.

Rethinking the above standard of Growth Collapses, does a relatively large economic slowdown in an economy entity mean that it is caught in middle-income trap? In fact, when faced with the reciprocal effects of domestic and international unfavorable factors, although the economy entity may experience a temporary decline of economic growth and meet the first two standards of Growth Collapses proposed by Eichengreen, et al., as long as its economic structure and quality are continuously improving, it is possible to successfully span the middle-income trap. For the late-developing economy entities, there are three kinds of growth slowdown in the process of catch-up: it is caused by the conversion in the growth stage, at this time, the late-developing advantage still exist but the change of their structure composing affects the potential growth; it is caused by the completion of release of late-developing advantage after the catch-up process is completed; the economy entities are caught in the middle-income trap. For example, China's current economic slowdown, in addition to being affected by the international economy, is more manifested in the above-mentioned first structural slowdown. 
In a reasonable identification standard, not only attention should be paid to the Growth Collapses of an economy entity in a particular period, but also judgment should be made based on its overall development history. In this sense, the standard of Eichengreen et al. only identified the short-term Growth Collapses of the economy entity, but ignored its long-term growth performance; while the standard of Felipe et al only identify the long-term growth performance of the economy entity, but fail to identify which specific periods existing "Growth Collapses" allow the trap to eventually emerge. Therefore, these two standards can be combined to judge on the basis of correcting the defects of the aforementioned standards.

Firstly, the sample range needs to be corrected. The purpose of this research is to provide reference for the late-developing economy entities to span the middle-income trap. The span time and stepping-over path required for the old developed economy entities that took the lead to enter the high-income group and the resource-based economy entities depending on oil export are significantly different from those of the late-developing economy entities. However, the standard of Eichengreen et al. only excluded oil-exporting economy entities; while the standard of Felipe et al. only excluded some developed economy entities. For example, Felipe et al. counted sample economy entities that entered the upper middle and lower middle-income groups from 1950. The upper middle-income group includes Denmark (entered the upper middle-income group in 1953), Sweden (1954), Netherlands (1955), Germany (1960), France (1960), Norway (1961), Belgium (1961), Italy (1963), Austria (1964), Finland (1964) and Japan (1968), which are old developed economies. In the research of Felipe et al., they are mixed with the newly industrialized economies such as the Four Asian Tigers to calculate the span duration threshold, which is obviously unreasonable. Therefore, this research changes the sample starting time of the upper middle-income group to 1970, and stipulates that the time for entering the high-income group should be later than 1980, so as to eliminate the old developed economies and make the identification standard more meaningful for the late-developing economy entities.

Secondly, there are still some abnormal data in the samples, which will have a great leverage effect on the identification standard. For example, in the study of Felipe et al., in addition to Oman which relies on oil exports, Costa Rica (entered the lower middle-income group in 1952), Bulgaria (1953) and Turkey (1955) are also included in the lower middle-income group. The time that those three economic entities spent spanning the lower middle-income stage was 54 years, 53 years and 50 years respectively, which are nearly twice as long as the rest of the samples in the same group. This is because, as mentioned above, there is a statistically significant relationship between the length of time an economy spans the lower middle-income stage and the time point entering this group. Apart from these three economy entities, in the rest of the samples which was took the lead to enter the lower middle-income group, Taiwan, China was 12 years later than Turkey. Therefore, this research changes the sample starting time of the lower middle-income group to 1960 to exclude these three economy entities.

Thirdly, the identification standard of median of the number of years used by Felipe et al. is too subjective. Moreover, the original group included early-developing and late-developing economy entities that have fully different span mechanism and span time, so its identification results are very sensitive to the change of sample economy entities. Therefore, the average value of span duration is used in this research to calculate the threshold of the identification standard. The specific results are shown in Tables 1 and Table 2 below.

Table 1. Economy Entities that Entered the Lower middle-income Group after 1960 and Successfully Promoted to the Upper middle-income Group

\begin{tabular}{ccccc}
\hline $\begin{array}{c}\text { Name of economy } \\
\text { entity }\end{array}$ & Region & $\begin{array}{c}\text { Time entering the lower } \\
\text { middle-income group }\end{array}$ & $\begin{array}{c}\text { Time entering the upper } \\
\text { middle-income group }\end{array}$ & $\begin{array}{c}\text { Number of years } \\
\text { required for } \\
\text { promotion }\end{array}$ \\
\hline China & Asia & 1992 & 2009 & 17 \\
Taiwan & Asia & 1967 & 1986 & 19 \\
South Korea & Asia & 1969 & 1988 & 19 \\
Malaysia & Asia & 1969 & 1996 & 27 \\
Thailand & Asia & 1976 & 2004 & 28 \\
\hline Average value & & & & 22 \\
\hline
\end{tabular}


Table 2. Economy Entities that Entered the Upper middle-income Group after 1960 and Successfully Promoted to the Upper Income Group

\begin{tabular}{ccccc}
\hline Name of economy entity & Region & $\begin{array}{c}\text { Time entering the } \\
\text { upper middle-income } \\
\text { group }\end{array}$ & $\begin{array}{c}\text { Time to entering the } \\
\text { upper-income group }\end{array}$ & $\begin{array}{c}\text { Number of years } \\
\text { required for } \\
\text { promotion }\end{array}$ \\
\hline Hong Kong & Asia & 1976 & 1983 & 7 \\
Taiwan & Asia & 1986 & 1993 & 7 \\
South Korea & Asia & 1988 & 1995 & 7 \\
Singapore & Asia & 1978 & 1988 & 10 \\
Mauritius & Africa & 1991 & 2003 & 12 \\
Chile & Latin America & 1992 & 2005 & 13 \\
Ireland & Europe & 1975 & 1990 & 15 \\
Spain & Europe & 1973 & 1990 & 17 \\
Portugal & Europe & 1978 & 1996 & 18 \\
Greece & Europe & 1972 & 2000 & 28 \\
Argentina & Latin America & 1970 & 2010 & 40 \\
\hline Average value & & & & 16 \\
\hline
\end{tabular}

To sum up, this research can set the identification standard for the economy entities caught in the middle-income trap and their caught time as follows: (1) According to the GDP per capita index in the Madison Project Database, the economy entity entered the high-income group after 1980 and does not belongs to resource-based economy entity that relies on oil exports; (2) GDP per capita of the economy entity was once in the lower middle-income group between US\$2,000 and US\$7,250, or in the upper middle-income group between US\$7,250 and US\$ 11,750; (3) For the economy entity that has advanced to the high income group, the economy entity spent more than 22 years entering the upper middle-income group from the lower middle-income group; or more than 16 years entering the high-income group from the upper middle-income group; (4) For the economy entity that has not advanced to the high income group, based on the expected duration that the entity will enters the high-income group in accordance with the growth rate of GDP per capita during the stay period in this group, judgement is made according to (3); (5) The average growth rate in seven years before the slowdown of the economy entity is more than or equal to $3.5 \%$; (6) The average growth rate in seven years after the slowdown of the economy entity is lower than that in the seven years before the slowdown by more than $2 \%$.

According to this identification standard, based on the previous calculation results, after excluding the old developed economy entities that entered the high-income group before 1980, the late-developing economy entities that the span duration exceeds the revised threshold can be found out. The specific results are shown in Table 3 and Table 4. 
Table 3. Economy Entities Caught in Lower middle-income Trap and Their Caught Years

\begin{tabular}{|c|c|c|}
\hline Name of economy entity & Region & $\begin{array}{l}\text { Years caught in lower } \\
\text { middle-income trap }\end{array}$ \\
\hline Malaysia & Asia & $1979-1983,1993-1995$ \\
\hline Thailand & Asia & $1991-1997$ \\
\hline Indonesia & Asia & $1992-1997$ \\
\hline Jordan & Asia & $\begin{array}{c}1961-1962,1964-1967, \\
1979-1986\end{array}$ \\
\hline Yemen & Asia & $1976-1982$ \\
\hline Brazil & Latin America & $1960-1962,1974-1980$ \\
\hline Peru & Latin America & $1965-1967$ \\
\hline Panama & Latin America & $1969-1973,1982-1983$ \\
\hline Jamaica & Latin America & $1970-1971,1973$ \\
\hline Dominican & Latin America & $1973-1978,1998$ \\
\hline Ecuador & Latin America & $1974-1979$ \\
\hline Guatemala & Latin America & $1977-1978$ \\
\hline Honduras & Latin America & $1978-1980$ \\
\hline Mexico & Latin America & $1979-1981$ \\
\hline Paraguay & Latin America & $1979-1983$ \\
\hline Argentina & Latin America & $1908-1910,1924$ \\
\hline Uruguay & Latin America & $1980-1981$ \\
\hline Algeria & Africa & $1960,1969,1978-1982$ \\
\hline Namibia & Africa & $1964-1968$ \\
\hline Swaziland & Africa & $1971-1976$ \\
\hline Tunisia & Africa & $1976-1978,1980-1981$ \\
\hline Egypt & Africa & $1980-1986$ \\
\hline Congo & Africa & $1981-1985$ \\
\hline Botswana & Africa & $1988-1993,2003$ \\
\hline Spain & Europe & 1967 \\
\hline Portugal & Europe & $1971-1975$ \\
\hline Greece & Europe & $1970-1971$ \\
\hline Albania & Europe & $1972-1973$ \\
\hline Romania & Europe & $1975-1977$ \\
\hline
\end{tabular}

Table 4. Economy Entities Caught in Upper middle-income Trap and Their Caught Years

\begin{tabular}{ccc}
\hline Name of economy entity & Region & Years caught in upper middle-income trap \\
\hline Malaysia & Asia & $1996-1998$ \\
Argentina & Latin America & $1970,1974,1996-1997$ \\
Uruguay & Latin America & $1997-1998$ \\
Spain & Europe & $1973-1979$ \\
Portugal & Europe & $1991-1992$ \\
Greece & Europe & $1972-1978$ \\
\hline
\end{tabular}

According to the identification results of ten newly industrialized economy entities identified by the Organization for Economic Cooperation and Development (OECD) in 1979: Four Asian Tigers all spanned lower middle-income trap and upper middle-income trap and became the high-income economy entities; Mexico and Brazil in Latin America failed to advance to the high-income economy entities and both of them had ever been caught in the lower middle-income trap; Greece, Portugal and Spain in Europe had become the high-income economy entities, but all had ever been caught in the lower middle-income trap and the upper middle-income trap; Yugoslavia is not considered because it had dismembered. Comparing Table 3 and Table 4, it can be found that there is a strong continuity between the upper middle-income trap and the lower middle-income trap and all the economy entities that had been caught in the upper middle-income trap also had been caught in the lower middle-income trap.

\section{Stepping-over Path of Middle-income Trap}

It can be seen from the results in Tables 1 to 4 that the economy entities that successfully spanned the middle-income trap include: Hong Kong, China, Taiwan, Korea, Singapore, Mauritius, Chile, and Ireland. From 
the view of stepping-over path, they can be divided into two categories: economy entities that have implemented the economic liberalization development model from the beginning, such as Hong Kong, Mauritius and Ireland, all belonging to this category. Economy entities that started from authoritarian governments and eventually achieved economic liberalization through gradually reducing government intervention in the process of economic development, such as Taiwan, Singapore, South Korea and Chile. They all followed the authoritarian development model. Their government used all kinds of resources to develop export processing industry. After rapidly escaping from the poverty trap, they quickly integrated into the global division of labor system under the information technology revolution. They made full use of the market mechanism, gradually reduced government intervention, and finally completed the overall economic and social transformation and spanned the middle-income trap. Therefore, if China wants to successfully overcome the middle-income trap, it should adhere to the market-oriented reform, expand its opening to the outside world, strengthen the construction of democracy and the rule of law, and ensure social fairness and stability.

\section{References}

Abu-Ghaida, D., \& Klasen, S. (2004). The Costs of Missing the Millennium Development Goal on Gender Equity, World Development, Elsevier, 32(7), 1075-1107. https://doi.org/10.1016/j.worlddev.2004.02.003

Aghion, P., Bloom, N., Blyundell, R., Griffith, R., \& Howitt, P. (2005). Competition and Innovation: An Inverted U Relationship, Quarterly Journal of Economics, 70-128. https://doi.org/10.2139/ssrn.1306944

Aiyar, S., Duval, R., Puy, D., Wu, Y. Q., \& Zhang, L.M. (2013). Growth Slowdowns and the Middle-Income Trap , IMF Working Paper. Retrieved from http:// 10.1016/j.japwor.2018.07.001

Barro, R., \& Sala-i-Martin, X. (1991). Convergence across States and Regions, Brookings Papers on Economic Activity, Economic Studies Program, 22(1), 107-182. https://doi.org/10.2307/2534639

Bruno, M., \& Easterly, W. (1998). Inflation Crises and Long-Run Growth, Journal of Monetary Economics, Elsevier, 41(1), 3-26. https://doi.org/10.1016/S0304-3932(97)00063-9

Duval, R., \& Maisonneuve, C. (2010). Long-Run Growth Scenarios for the World Economy, Journal of Policy Modeling, 32, 64-80. https://doi.org/10.1016/j.jpolmod.2009.10.001

Eichengreen, B., Park, D., \& Shin, K. (2011). When Fast Growing Economies Slow Down: International Evidence and Implications for China.NBER Working Paper 16919. Retrieved from https://www.nber.org/papers/w16919.pdf.

Felipe, J., Abdon, A., \& Kumar, U. (2012). Tracking the Middle-income Trap: What Is It, Who Is in It, and Why? The Levy Economics Institute Working Paper No. 715. Retrieved from https://doi.org/10.2139/ssrn.2049330

Fischer, S. (1993). The Role of Macroeconomic Factors in Growth, Journal of Monetary Economics, 32(3), 485-512. https://doi.org/10.1016/0304-3932(93)90027-D

Magnus, J. R., Powell, O., \& Prüfer, P. (2010). A Comparison of Two Model-Averaging Techniques with an Application to Growth Empirics. Journal of Econometrics, 154, 139-153. https://doi.org/10.1016/j.jeconom.2009.07.004

Tenreyro, S. (2007). On the Trade Impact of Nominal Exchange Rate Volatility, Journal of Development Economics, Elsevier, 82(2), 485-508. https://doi.org/10.1016/j.jdeveco.2006.03.007

\section{Copyrights}

Copyright for this article is retained by the author(s), with first publication rights granted to the journal.

This is an open-access article distributed under the terms and conditions of the Creative Commons Attribution license (http://creativecommons.org/licenses/by/4.0/). 